\title{
Geospatial Analysis of Desalination in the US - An Interactive Tool for Socio-Economic Evaluations and Decision Support
}

\author{
Jadwiga R. Ziolkowska ${ }^{1 *}$ and Reuben Reyes ${ }^{2}$
}

\author{
${ }^{1}$ The University of Oklahoma, Department of Geography and Environmental Sustainability, 100 \\ East Boyd St. SEC 650, Norman, OK 73019-1081, United States, Phone: (405) 325-9862, \\ jziolkowska@ou.edu \\ ${ }^{2}$ The University of Oklahoma, Oklahoma Climatological Survey, 120 David L. Boren Blvd., \\ Suite 2900, Norman, OK 73072, United States, Phone: (405) 325-9512, reuben.reyes@ ou.edu \\ *Corresponding author: Jadwiga R. Ziolkowska
}

\begin{abstract}
In the United States, desalination has considerably expanded since the 1950s, reaching a daily production capacity of 2 BGD (billion gallons per day) with around 1,336 operating plants as of 2013 (GWI, 2013). Despite this continuous growth, a steady increase in desalination investments and growing demand for water, research on geospatial representation of desalination plants and their characteristics over time does not exist or is very limited. This paper aims at filling this gap by developing interactive 5D and 6D geospatial models and a multi-dimensional analysis of desalination trends in the time span 1950-2013. The analysis shows that desalination plants are located mainly on the East and West Coast of the United States, with Florida, California, and Texas leading in the national desalination sector. Despite the geographical proximity to the sea, most of the plants use brackish groundwater due to economic factors related to the desalination process itself and the disposal of the highly saline byproduct - brine. The models can be used both for educational and interdisciplinary research purposes and help with determining socioeconomic viability of establishing prospective desalination plants in different regions in the future. They can also help support decision makers in solving emergency questions related to water shortages and preparing for long-term water scarcity in different US regions.
\end{abstract}

Keywords: Desalination, geospatial models, multi-dimensional analysis, spatio-temporal analysis, US 


\section{Introduction - Need and challenges for geographical representation of desalination}

plants in the US

As reported by the US Census Bureau (2012), the United States population is expected to increase by $31 \%$ by 2050 . For many decades, water demand for food, fuel, industrial, and municipal consumption has been growing rapidly, while water resources were shrinking either due to the aquifers depletion or due to unexpected weather events like drought. Thus, the availability of fresh water is endangered and poses a serious challenge for policy makers. Desalination is one of the technologies that could help mitigate this problem in the mid- and long-term.

With the total desalination capacity in the US of 2 BGD (billion gallons per day) and the total of 1,336 operating plants in 2013, the US is competing with Saudi Arabia for the top place on the global desalination market in terms of the annual production capacity. The desalination sector has been growing exponentially since 1990s - the total capacity increased by 53 times and the total number of plants by 61 times between 1990 and 2013 (GWI, 2013). The annual rate of growth by the number of new desalination plants online in the US indicates long-term trends in the desalination sector (Fig. 1). At the same time, the total global investments in desalination reached the low of $\$ 3.5$ billion in 2013 and are expected to grow up to $\$ 12$ billion by 2018 (Gasson, 2013). Desalination is still an expensive technology, but it has a tremendous potential for 'enormous supply expansion that exceeds all likely demands' (Chowdhury et al., 2013). 


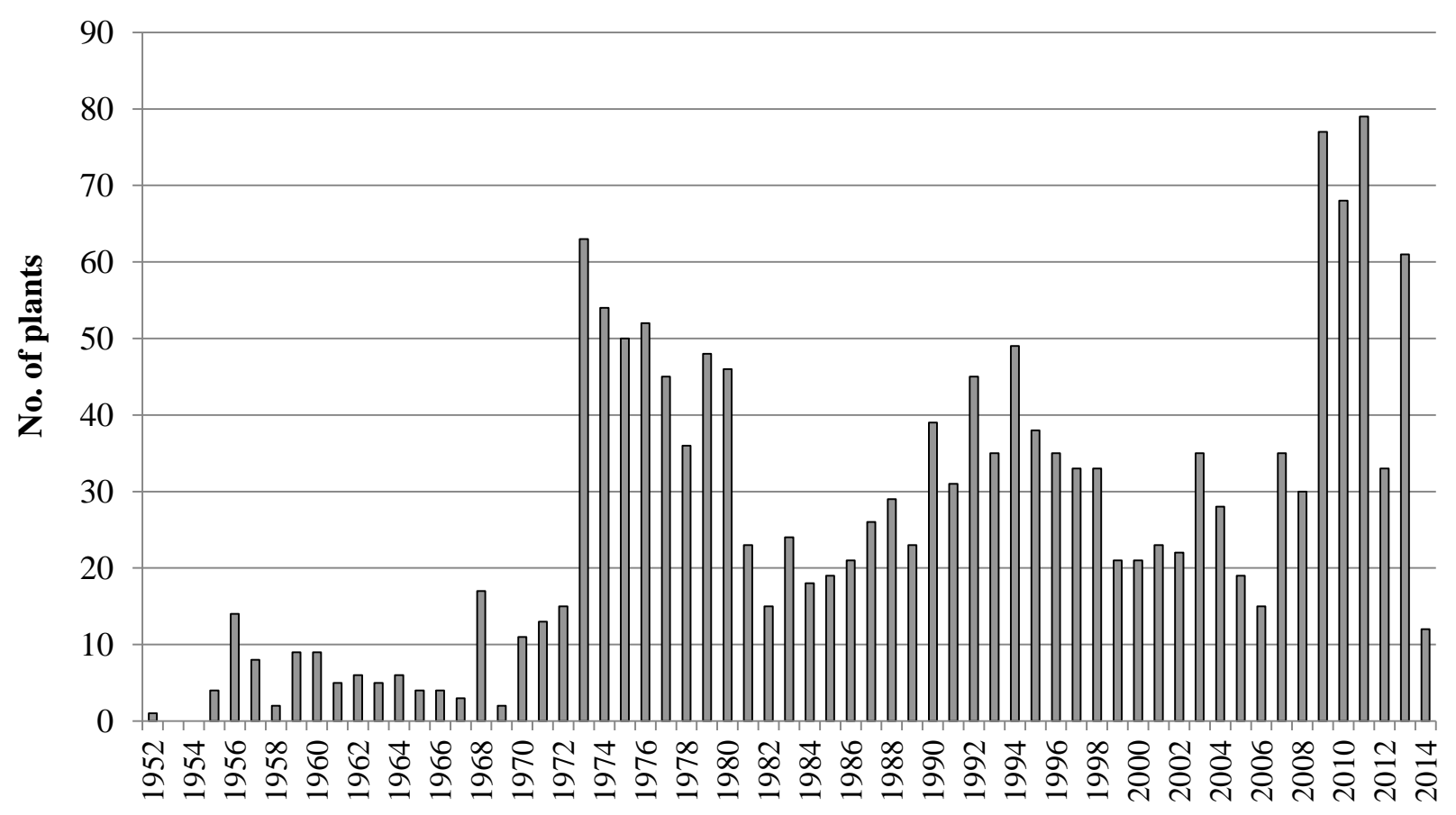

Fig. 1. New desalination plants online in the US per annum Source: Authors' presentation based on GWI (2013)

Even though desalination has been successfully applied in the US as a reliable water supply source since 1950s, congruent and detailed information on the respective desalination plants is still missing to date. The collection of desalination data is extremely difficult mainly because of constant dynamics in the desalination sector, while it is also stymied by private BOT (BuildOperate-Transfer) arrangements between municipal water authorities and construction companies that do not always allow for the information to become a public record for many years after the desalination plants are built.

Due to data paucity, most researchers attempt to compile desalination information based on regional case studies (Cooley et al., 2006, 2012; WUIM, 2009). Those studies represent only a limited selection of existing desalination plants or future anticipated projects without any detailed specifications; and thus they do not provide enough input to depict a comprehensive picture of the desalination sector in the US. In addition, the regional data is often outdated and not comparable with other regions, due to diverse methodologies applied for different case studies in different regions. 
Several studies have attempted to combine and map desalination projects, however, with a limited success. For instance, Cooley et al. (2006) depicted trends on the global desalination market and mapped only the recently proposed desalination plants in California as of spring 2006. In 2014, the Bureau of Reclamation (2014) represented solely the single numbers of the most recent desalination projects ${ }^{1}$ in the respective states, without providing detailed and specific information about those projects or their geolocation. Similarly, TWDB (2014) displayed only the largest plants in Texas, also missing on providing detailed information and a broader regional analysis. At the international level, similar attempts have been undertaken by Höpner and Lattemann (2002), Lattemann and Höpner (2008), and Dawoud and Mulla (2012) to map regional seawater desalination capacity in the Arabian Gulf. However, those studies have not been more comprehensive in terms of mapping desalination plants than the studies conducted in the US.

As of today, comprehensive studies are missing that would provide detailed geographic interactive maps of desalination plants in the US, and - due to the difficulties described above no scientific effort has been taken to provide a compiled tool (model) to analyze all desalination plants in the country in a congruent way. This paper aims at filling this gap by developing fiveand six-dimensional (5D and 6D) interactive models that represent desalination plants in the US in a geospatial location over the last six decades. This research coincides with a study by Eckert et al. (2016) who emphasized that a detailed spatial analysis is necessary to draw meaningful conclusions about the phenomena under investigation. By including a set of uniform variables for all analyzed plants (feed water, establishment date, production capacity, users of desalinated water) in one interactive geospatial and temporal map, the models and visual representation allow for comparison analyses among plants.

The models present the desalination sector on a macro scale. They can be used for analyzing trends in desalination as they address both changes in the plant status (online, offline, mothballed, decommissioned, under construction, etc.) and changes in desalination capacity at all those plants over time since 1950s. The models are 3D fly-through clickable GIS maps with a Radio folder feature selection function allowing for turning on and off different feature layers and categories, depending on the conduced analysis. This determined the interactive capability of

\footnotetext{
${ }^{1}$ A desalination project should be understood as a pilot project used for assessing validity of establishing a desalination plant in a given location in the future.
} 
the model and allows the user to explore different multi-dimensional GIS features of desalination plants presented with the model. This model functionality also fosters quick learning and provides the user with a tool for an in-depth multi-dimensional exploration of the trends and changes in the desalination sector.

The models are multi-dimensional which means that they combine multiple categories describing desalination plants: 1) location - represented with the lat long (and the $\mathrm{x}$, y axes) describing the geospatial feature, 2) time - represented with the elevation (and the $\mathrm{z}$ axis) describing spatiotemporal feature, and 3) additional desalination characteristics, such as feed water, capacity, plant status, and the user category. Those categories allow for the exact geographical and temporal determination and specification of the desalination plants in the US, including all the above mentioned characteristics simultaneously. The information generated with the models can be useful for estimating socio-economic viability of new desalination plants in the specific geographical locations in the future.

\section{Benefits of visualization techniques for interactive geospatial desalination representation}

In order to represent desalination plants in the US with comprehensive geospatial and spatiotemporal models, we apply multi-dimensional computer visualization techniques that allow the models to be used in any virtual globe (Google Earth, NASA World Wind, and ESRI's ArcExplorer).

In recent decades, computer graphics visualization and imaging have experienced a rapid growth and captured the interest of governments, scientists, and business representatives (Fox and Hendler, 2011). The idea of a virtual globe (a computer application allowing users to browse and search data projected on a cartographic representation of the Earth) emerged at the end of the last millennium (Bailey, 2010). With the development of the XML-based markup language KML (Keyhole Markup Language) - open source, tag-based scripting language, interactive digital cartography became possible in all major virtual globes (De Paor and Whitmeyer, 2011). Visualization techniques have been acknowledged to provide a powerful way to 'take advantage of human abilities to perceive visual patterns and to interpret them' (Costabile and Malerba, 2003; Kopanakis and Theodoulidis, 2003; Andrienko et al., 2003, 2011; Compieta et al., 2007). 
Furthermore, multi-dimensional visualization has been successfully applied in many studies (Angsüsser and Kumke, 2001; Yufen, 2001; Krisp, 2004; Su et al., 2016).

The models presented in this paper offer the possibility to dynamically interact with desalination data in a spatial and temporal view. They extend the current knowledge in the field and meet the scientific and visualization needs as specified above and expressed by many scientists (Compieta et al., 2007; Dransch et al., 2010; Shneiderman, 2002; Van de Weghe et al., 2014).

Nowadays, most 3D models are based on and apply specific visualization software that is not always freely accessible to anyone, requires specialized graphic cards or hardware and/or is difficult to use as it involves a long learning process. Virtual globe applications do not have any special technical requirements in this regard and are capable of loading and rendering standard KML files. This feature facilitated the research presented in this paper and other previous studies (Neutens et al., 2010; Yang et al., 2012). It allowed us to develop desalination models that would be accessible to any computer user. The techniques presented in this paper provide not only a visualization tool, but also an exploration tool that, as advocated by Fox and Hendler (2011), 'scientists can use throughout the research life cycle' not only to represent the final research results, but to look for and interactively explore hidden patterns and relations that would not be detectable solely with raw data sets.

\section{$3 \quad$ Methodology and data}

The interactive geospatial multi-dimensional visualization models for the desalination plants in the US are based on the data set from Desaldata.com by the Global Water Intelligence (GWI) (2013). With its 2,749 entries $^{2}$ for the US in 2013 it is the most comprehensive and extensive desalination data base so far. Due to constant changes in the desalination sector and new desalination plants approved and established on a regular basis, we appreciate that the data base is not complete due to continuous dynamics in the sector. It is also inaccurate at times, mainly due to inconsistencies of the geographical location of the desalination plants. In order to eliminate data inaccuracies and prevent potential biases in our consequent analysis, as well as to provide a consistent data and modeling base, we filtered out entries with missing states or cities that are crucial to determine the exact geolocation of the plants. Data cleaning was an essential

\footnotetext{
${ }^{2}$ The number includes all plants on file: operating plant, mothballed and decommissioned plants, and plants under construction.
} 
part of the model building to insure its robustness. In this way, we specified the total of 1,600 plants in the US with complete records for four main variables included in this analysis: plant capacity, raw water type, user category, and plant status.

A relevant part of the research presented in this paper is geocoding that allowed us to find and assign the address of the respective desalination plans within a virtual globe space. Based on the raw GWI data we used the combination of Google Fusion tables and Google Earth to perform geocoding and convert the locations of all plants into latitude and longitude (lat long) with the Keyhole Markup Language (KML) that has been established as a standard scripting language for scientific research in virtual globes (de Paor and Whitmeyer, 2011). Since Google Earth is acknowledged to provide the best geocoding function as of today (de Paor et al., 2010), the validity of the geocoding process is high (Angel et al., 2008). Subsequently, due to the geocoding process, the final results of our models can be viewed in ArcGIS, ArcMap, ArcGIS Explorer, NASA World Wind, Google Maps (GM), and Google Earth (GE). The models can be used on any computer system: Windows, Linux, Apple, and on smartphones: iPhone, iPad or Android.

Based on the geocoding results, we used the $\mathrm{C}++$ computing language to create a 3D analysis space in the first place. We determined four different types of categories for the desalination analysis and assigned value ranges to the respective visual representation shapes (spheres), while the respective categories to corresponding colors (Table 1). 
Table 1. Categories for the desalination plants in the US

\begin{tabular}{|c|c|}
\hline Category & Category variable \\
\hline Plant capacity (MGD*) & $\begin{array}{l}4.31<73.21 ; 1.80<4.31 ; 0.86<1.80 ; 0.50<0.86 ; 0.31<0.50 ; \\
0.20<0.31 ; 0.13<0.20 ; 0.08<0.13 ; 0.04<0.08 ; 0.00<0.04\end{array}$ \\
\hline Raw water type (TDS) & $\begin{array}{l}\text { Brackish water or inland water (TDS** } 3000 \text { - <20000) } \\
\text { Brine or concentrated seawater (TDS >50000) } \\
\text { Pure water or tap water (TDS <500) } \\
\text { River water or low concentrated saline water (TDS } 500-<3000 \text { ) } \\
\text { Seawater (TDS } 20000 \text { - 50000) } \\
\text { Waste Water } \\
\text { Unknown }\end{array}$ \\
\hline User category & $\begin{array}{l}\text { Demonstration } \\
\text { Discharge } \\
\text { Industry (TDS <10) } \\
\text { Irrigation (TDS <1000) } \\
\text { Military purposes (TSD } 10-<1000) \\
\text { Municipalities as drinking water (TDS } 10-<1000) \\
\text { Power stations (TDS <10) } \\
\text { Tourist facilities as drinking water (TDS } 10-<1000 \text { ) } \\
\text { Water injection } \\
\text { Unknown }\end{array}$ \\
\hline Plant status & $\begin{array}{l}\text { Cancelled; Construction; Offline (Decommissioned); On Hold; } \\
\text { Online; Planned; Presumed online; Presumed offline }\end{array}$ \\
\hline
\end{tabular}

Legend: MGD* - million gallons per day, 1 US gallon $=3.78541$ liters. TDS $* *[p p m]-$ total dissolved solids (indicates salinity level) measured in ppm (parts per million). The TDS levels were applied according to the specification provided in the Desaldata.com data base.

Each category represents 5 dimensions: (1) latitude (x axis), (2) longitude for geographical location (y axis), (3) year represented as elevation (z axis), (4) MGD (million gallons per day production capacity) represented as the size of the sphere, and (5) color as the type within each category. Because we deal with three additional categories (plant status, raw water type, final user), the category itself is another dimension, thus giving us the total of six dimensions (and a 
$6 \mathrm{D}$ model) to represent in the virtual globe. To add the $6^{\text {th }}$ dimension to the analysis we combined exclusive switching Radio folders for the featured characteristics of the desalination plants. The value range for the MGD category was determined with the probability density function and was based on the normal data distribution for the production capacity. Unsupervised binning with equal frequency partitioning was applied that divided the desalination capacity range into $\mathrm{n}$ intervals, each containing approximately the same number of samples. This method has been acknowledged as a good data scaling approach for visualization purposes (Levnaji and Mezi 2010). This distribution (and interval ranges) was also most plausible from the scientific point of view due to the high percentage of small desalination plants ( $90 \%$ of all observations).

Based on the specifications mentioned above, we generated five models in total: one 4D model (using color and the size of the spheres to represent desalination capacity), three 5D models (representing different categories of desalination plants), and one 6D model (representing a group of categories) (fig. 2). This variety of the multi-dimensional models allows for a broad visual representation and analysis of the desalination plants across the US. Each model displays a different characteristic of desalination (plant size/production capacity, date the plant started operation, current plant status, raw water type, and final users of desalinated water). 


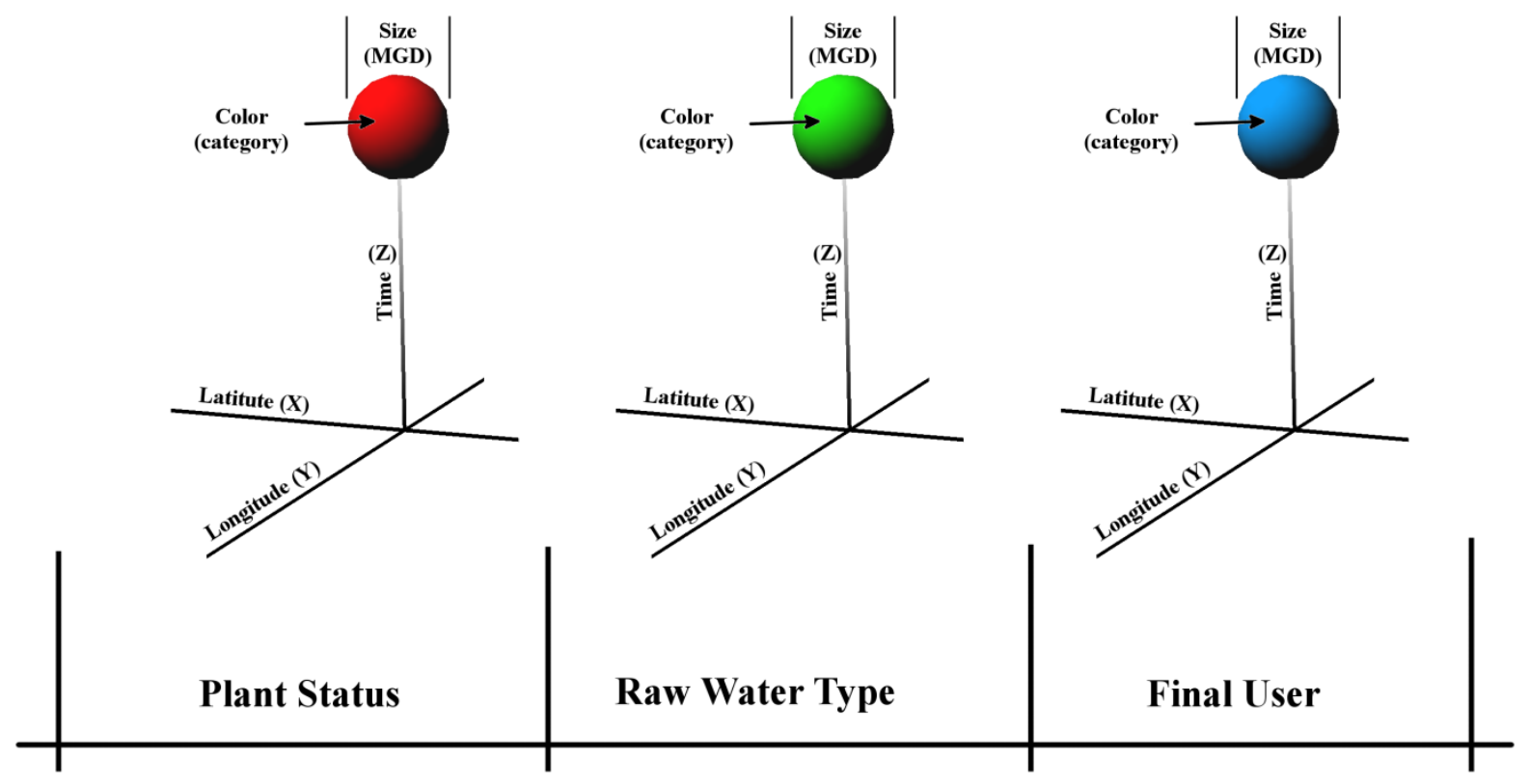

Fig. 2. Graphical representation of the $6 \mathrm{D}$ model

Source: Authors' presentation

Each desalination plant in the interactive geospatial models is a data point represented by a 3D colored sphere that is described in more detail in a Google Earth window, when the model user clicks on a sphere representing the desalination plants (fig. 3). 


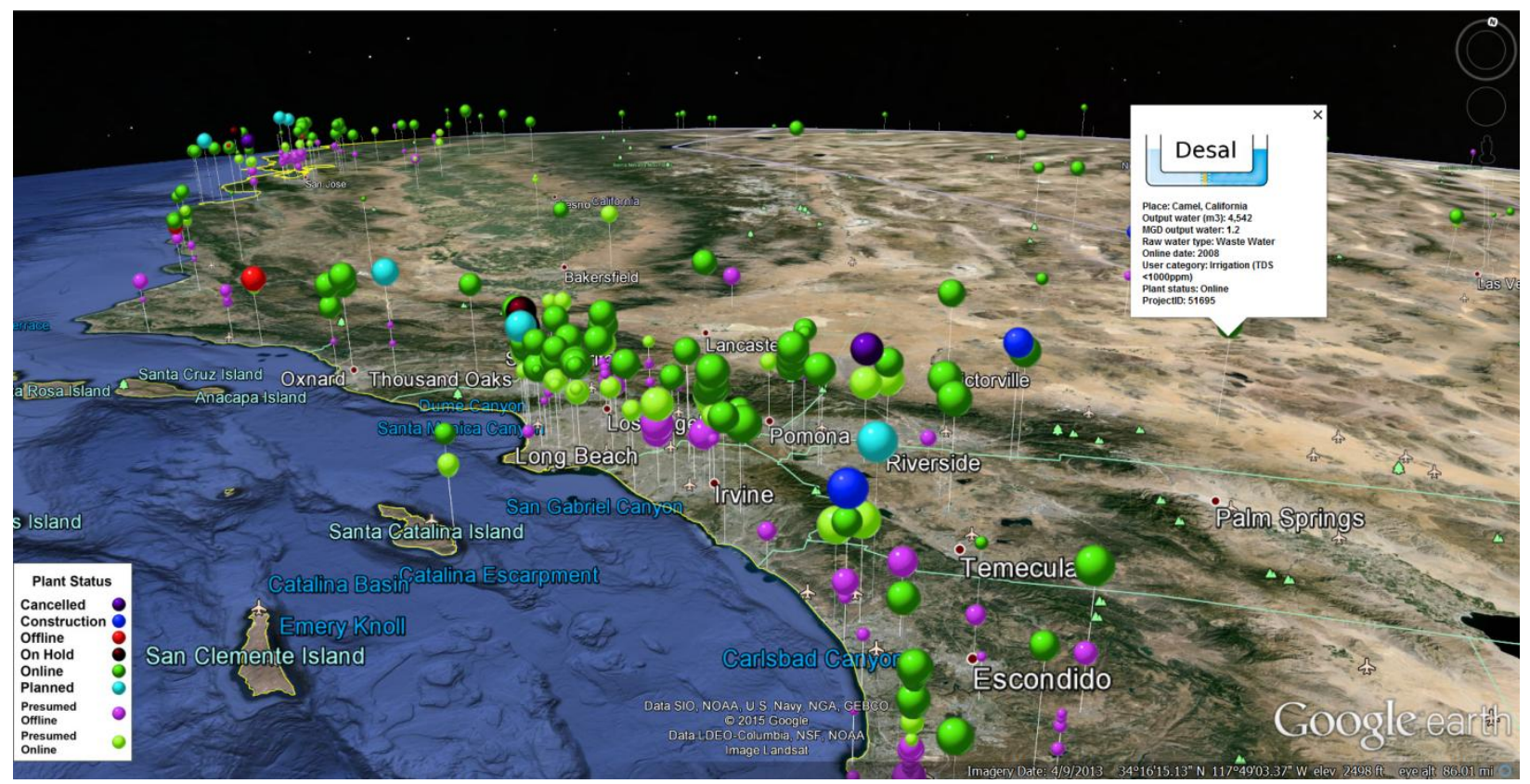

Fig. 3. 5D map of desalination plants in the US based on plant status category and with interactive information pop-up window about the plants

Source: Authors' presentation

\section{$4 \quad$ Results and discussion}

The interactive models for the desalination plants in the US can be used interactively in a virtual globe and accessed by any user with Internet connection (the link to the models is provided at the end of the paper). The direct benefit of the models is that they allow for a quick evaluation and analysis of several different characteristics of desalination plants in the US simultaneously, as well as for a comparison analysis of different plants in different geolocations.

Fig. 4 shows the distribution of the desalination plants in the US based on the plant production capacity. It needs to be emphasized that more than $90 \%$ of all the plants in the US are small-scale plants with the capacity below 4.31 MGD. This determined the scale range for the visual representation. Most of the plants, and especially larger plants with the capacity above 4.31 MGD are located on the US East Coast, as well as in California, Texas, Oklahoma, and Florida, as they can use seawater for desalination. Some larger plants are also present in Illinois and Colorado. The vast majority of plants in the country operate with a capacity in the range between 
0.31 MGD and 1.80 MGD. The models allow for analyzing plants in terms of the desalination capacity, but also in terms of the end user, water source, and the plant status.

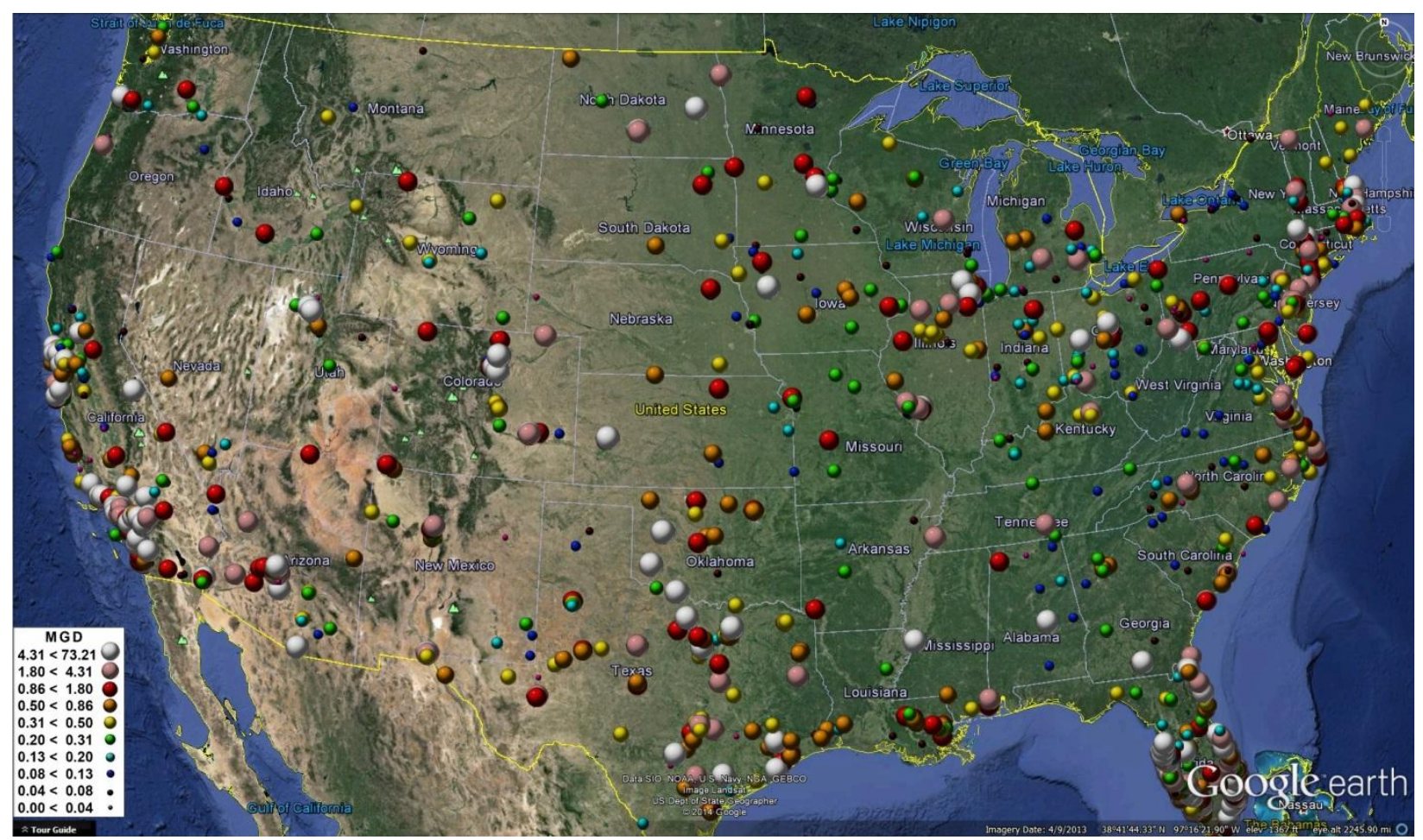

Fig. 4. 5D map of desalination plants in the US based on desalination capacity

Source: Authors' presentation

Fig. 5 shows a screen shot of desalination plants in the area of Los Angeles, which produce desalinated water mainly for municipal purposes (drinking water) and for the industry sector. This is also the case for most of the desalination plants in the US. An exemption is Florida where most of the desalination plants desalinate water for municipal use. The white lines in the figure connect the sphere with the surface of the Earth pointing the exact location of the plant. The features and categories can be turned on and off in the virtual globe environment, which allows for a focused analysis, determining local needs in terms of water supply from the desalination plants, and finally designing strategies for an effective short- and long term water allocation. 


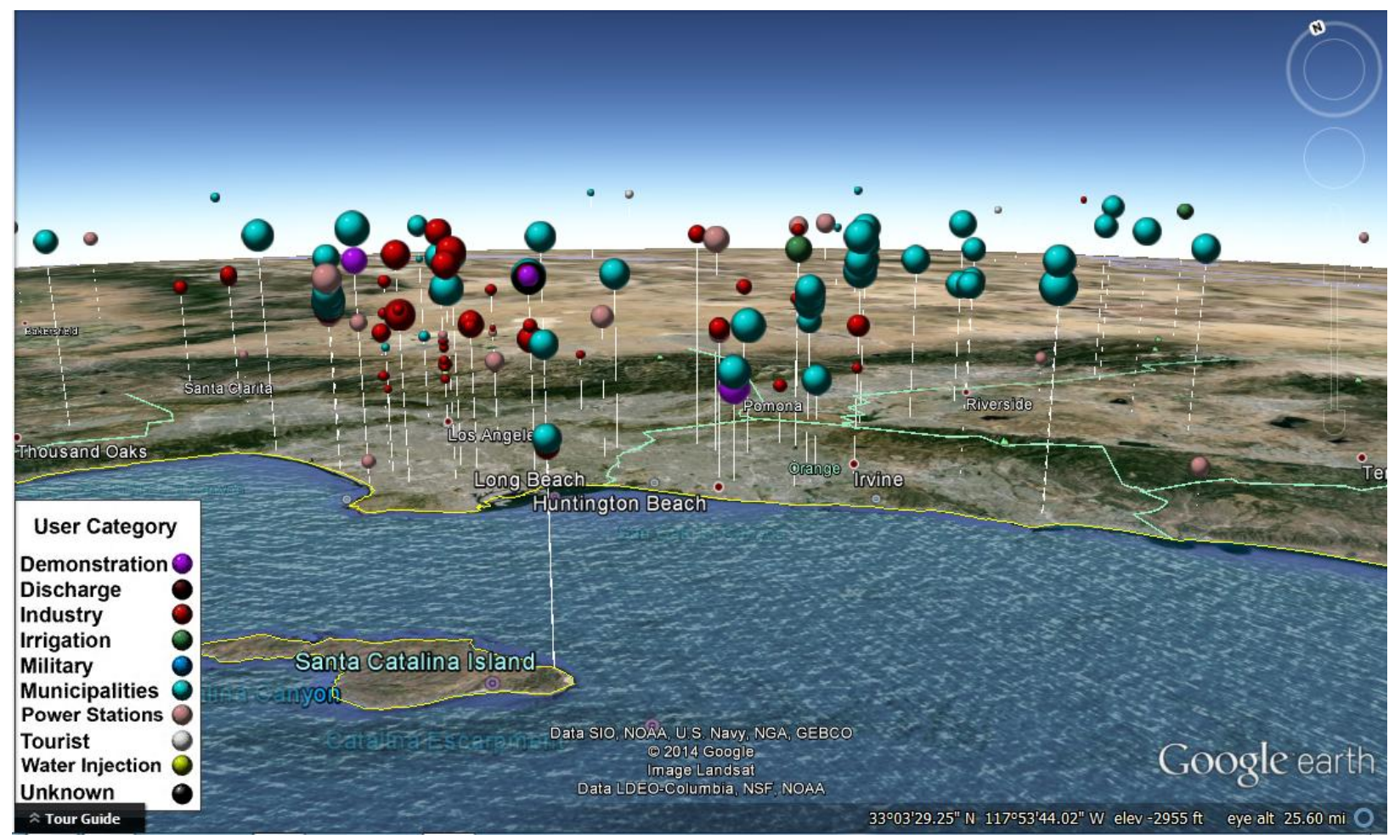

Fig. 5. 5D view of desalination plants in the Los Angeles area based on end consumer of desalinated water

Source: Authors' presentation

The analysis of the water sources for desalination (feed water) shows that around $55 \%$ of the desalination plants in the US use brackish groundwater and they are located inland. Almost $29 \%$ of the plants use surface water (river or lake water) and $\sim 8 \%$ waste water (fig. 6). 


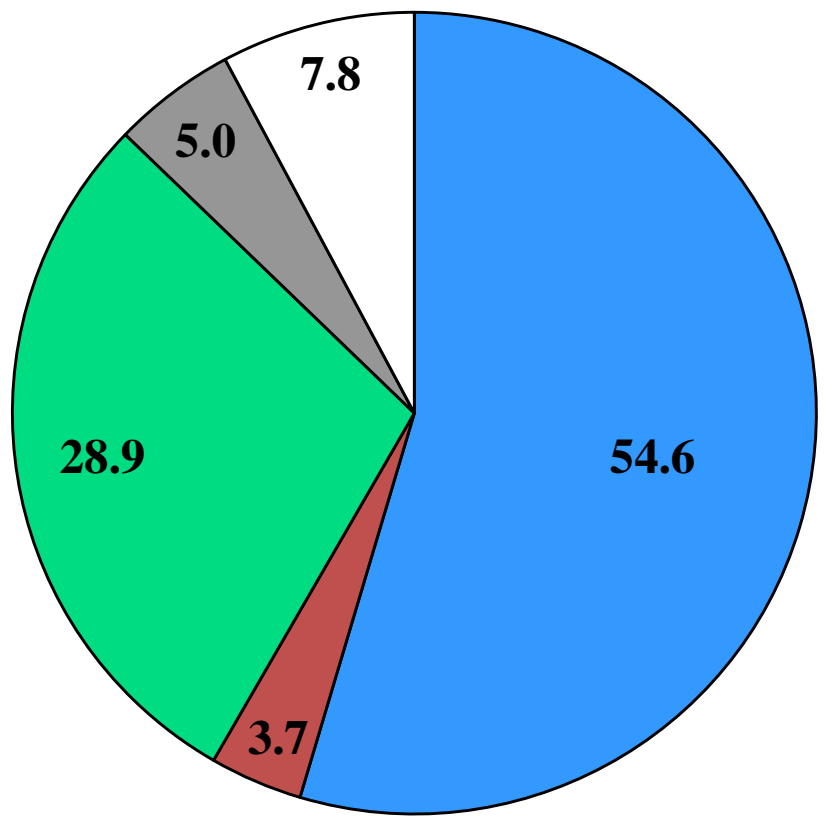

Fig. 6. Feed water for desalination in the US (\%)

Source: Authors' presentation based on data from GWI (2013)

Desalination plants using seawater are located along the US coast; however, also highly saline water in the inland of the country is used for desalination. The 'seawater' term is used as a common standard for any saline waters with TDS ranges between 20,000 and 50,000 ppm. Therefore, the 'seawater' spheres found in Kansas, Alabama, Georgia, Pennsylvania, and California, represent highly saline feed water and not seawater per se. Most of the desalination plants in the US are online (operating), while only three plants (in California, New Mexico, and Texas) have been on hold as of 2013. Two plants: Santa Barbara, CA and Zion, IL are offline (either mothballed or decommissioned). Several plants in California, Texas, Mississippi, Florida, Utah, North Carolina, Ohio, and New York are under construction or planned to be constructed in the future.

Representing information about the desalination plants in the US by means of the geospatial models developed with this research provides a perpetual added-value to the scientific 
community and regional decision makers. It can help decision makers with determining economic regions with the highest needs for additional water supply in the future, which in turn can further help with evaluating socio-economic impacts on the region and the entire country as a result of establishing new desalination plants.

The temporal and geographical visualization of desalination plants provided with the models can be useful to decision makers and enable them to: 1) learn about existing desalination plants, their locations and characteristics, and 2) extend their knowledge about experiences at those plants and feasibility of desalination in a given region, at one glance. An analysis of this kind is not possible by evaluating raw numbers in a spreadsheet. With the presented models, a decision maker can visually and quickly learn and assess, among others, the following factors: a) municipal agglomerations close to desalination plants, b) how many plants were built in different regions (or in a specific region of decision maker's interest) and in what specific year, c) how long have they been operating till a replacement with a newer plant took place, d) how much water do they produce and have been producing at different stages of their operation since their establishment, e) what water source has been used for desalination, and $f$ ) who is the final consumer of desalinated water (municipalities, industry, power generation sector, military, tourist facilities etc.). This information further allows for a direct evaluation of water supply and water demand in a given region that the plants are satisfying (or helping to satisfy as a part of a municipal or industrial water portfolio). For a decision makers anticipating a new desalination plant in a specific region, at one glance the model can provide information about economic feasibility of a potential new plant based on the access to feed water, energy sources, water demand, and experiences of other plants in that region. The presented models can also be used to design mid- and long-term plans for potential emergency situation of water scarcity due to drought or other unexpected weather events.

\section{$5 \quad$ Conclusions and outlook}

As of today, visual, geospatial or interactive representation of desalination plants in the US are missing, while the desalination market and the public, private, and scientific interest in desalination are rapidly growing. Thus, the presented geospatial interactive models provide a uniform and unique representation of desalination data and can further help with planning and 
designing new desalination plants in the future, considering socio-economic conditions in different regions. The models use multi-dimensional data and facilitate a better understanding of and a comprehensive interaction with different data dimensions. The models are spatiotemporally oriented with the geographical location, color and size of the spheres representing different data components and categories.

The main benefit of the presented models is that they deliver complicated data sets and make its use dynamically interactive and easy via the web to any Internet user on any modern computer system application (Windows, Mac, Linux, and mobile phones).

We propose the models to be used as an educational and research tool to better analyze, present, and display water issues and the developments of the desalination sector in the US. They can be used as a decision-support tool by policy makers and other stakeholders. By covering geographical and spatio-temporal data they can be used for designing policies and measures at the regional and national scale. This is especially important with relevant policy questions regarding water scarcity in many regions in the country. Further research in the field can help to develop interdisciplinary collaborations between scientists, engineers and other stakeholders to better cope with unexpected events like drought (and the resulting water shortage).

\section{$\underline{\text { Model access: }}$}

The models and a video on how to navigate through the model can be found here: http://www.hitechmex.org/US_desal/US_desal.html

\section{$\underline{\text { Acknowledgment }}$}

The research was supported by the Oklahoma NSF EPSCoR Program OIA-1301789 and Oklahoma Climatological Survey (Mesonet). 


\section{References}

Andrienko, G., Andrienko, N., Keim, D., MacEachren, A.M., and S. Wrobel, 2011. Challenging problems of geospatial visual analytics, Journal of Visual Languages and Computing 22: 251-256.

Andrienko, N., Andrienko, G., and P. Gatalsky, 2003. Exploratory spatio-temporal visualization: an analytical review, Journal of Visual Languages and Computing, special issue on Visual Data Mining 14(6): 503-541.

Angel, A., Lontou, C., Pfoser, D., and A. Efentakis, 2008. Qualitative Geocoding of Persistent Web Pages. ACM GIS Meeting, November 5-7, 2008. Irvine, CA, USA.

Angsüsser, S., Kumke, H., 2001. 3D visualization of theWatzmann-Massif in Bavaria of Germany. Journal of Geographical Sciences 11(1): 63-68.

Bailey, J., 2010. Virtual globes, Encyclopedia of Geography (Warf, B., editor), Sage Publications Inc., Los Angeles, CA, pp. 3528.

Bureau of Reclamation, 2014. Desalination and Water Purification Research Program Cost Share and Location. In: http://www.usbr.gov/research/AWT/DWPR/cost-share.html (06/13/2015)

Chowdhury, F., Lant, C., Dziegielewski, B., 2013. A century of water supply expansion for ten U.S. cities. Applied Geography 45: 58-76.

Compieta, P., Di Martino, S., Bertolotto, M., Ferrucci, F., and T. Kechadi, 2007. Exploratory spatio-temporal data mining and visualization, Journal of Visual Languages and Computing 18: $255-279$.

Cooley, H., Ajami, N. 2012. Key issues for desalination in California: cost and financing. Pacific Institute, Oakland.

Cooley, H., Gleick, P.H., and G. Wolff, 2006. Desalination with a grain of salt. A California Perspective. Pacific Institute, Oakland.

Costabile, M.F., and D. Malerba, 2003. Special issue on visual data mining, Journal of Visual Languages and Computing 14: 499-501.

Dawoud, M.A., Al Mulla, M.A., 2012. Environmental Impacts of Seawater Desalination: Arabian Gulf Case Study, International Journal of Environment and Sustainability 1(3): 2237.

De Paor, D.G., and S.J. Whitmeyer, 2011. Geological and geophysical modeling on virtual globes using KML, COLLADA, and Javascript, Computers \&Geosciences 37: 100-110. 
De Paor, D.G., Dordevic, M., and S.C. Wild, 2010. Using Google Earth to Visualize the Core, Mantle, and Crust in Four Dimensions. American Geophysical Union, Fall Meeting 2010.

Dransch, D., Köthura, P., Schulte, S., Klemann, V., and H. Dobslaw, 2010. Assessing the quality of geoscientific simulation models with visual analytics methods - a design study, International Journal of Geographical Information Science 24(10): 1459-1479.

Eckert, S., Giger, M., Messerli, P., 2016. Contextualizing local-scale point sample data using global-scale spatial datasets: Lessons learnt from the analysis of large-scale land acquisitions. Applied Geography 68: 84-94.

Fox, P., and J. Hendler, 2011. Changing the Equation on Scientific Data Visualization, Science, 331: 705.

Gasson, C., 2013. Desalination market update. Fourth Quarter Assessment. Water desalination report 2013.

GWI (Global Water Intelligence), 2013. Market profile and desalination markets, 2009-2012 yearbooks and US desalination plants inventory. GWI: Oxford (Data provided to the authors and used with written permission).

Höpner, T., Lattemann, S., 2002. Chemical impacts from seawater desalination plants - a case study of the northern Red Sea, Desalination 152: 133-140.

Kopanakis, I., and B. Theodoulidis, 2003. Visual data mining modeling techniques for the visualization of mining outcomes, Journal of Visual Languages and Computing 14(6): 543589.

Krisp, J.M., 2004. Three-dimensional visualisation of ecological barriers. Applied Geography 24(1): $23-34$.

Lattemann, S., Höpner, T., 2008. Environmental impact and impact assessment of seawater desalination, Desalination 220: 1-15.

Levnaji, Z., Mezi, I., 2010. Ergodic Theory and Visualization I: Mesochronic Plots for Visualization of Ergodic Partition and Invariant Sets. Chaos 20: 033114.

Neutens, T., Versichele, M., Schwanen, T. 2010. Arranging place and time: A GIS toolkit to assess person-based accessibility of urban opportunities. Applied Geography 30(4): 561-575.

Shneiderman, B., 2002. Inventing discovery tools: combining information visualization with data mining, Information Visualization 1(1): 5-12.

Su, T., Cao, Z., Lv, Z., Liu, C., Li, X., 2016. Multi-dimensional visualization of large-scale marine hydrological environmental data. Advances in Engineering Software 95: 7-15. 
TWDB (Texas Water Development Board), 2014. Brackish Groundwater and Desalination Plant Maps. TWDB, Austin.

US Census Bureau, 2012. 2012 National Population Projections, USCB: Washington.

Van de Weghe, N., de Roo, B., Qiang, Y., Versichele, M., Neutens, T., and P. de Maeyer, 2014. The continuous spatio-temporal model (CSTM) as an exhaustive framework for multi-scale spatio-temporal analysis. International Journal of Geographical Information Science 28(5): 1047-1060.

Water Utility Infrastructure Management (WUIM), 2009. Desalination in the United States. The Journal of Finance and Management for Water and Wastewater Professional. July/August 2009.

Yang, X., Jiang, G.M., Luo, X., Zheng, Z., 2012. Preliminary mapping of high-resolution rural population distribution based on imagery from Google Earth: A case study in the Lake Tai basin, eastern China. Applied Geography 32(2): 221-227.

Yufen, C., 2011. Map spatial cognition research and spatial information visualization. Journal of Geographical Sciences 11(1): 79-85. 


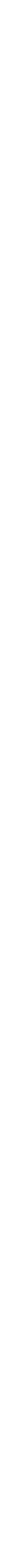

${ }^{-}$

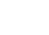
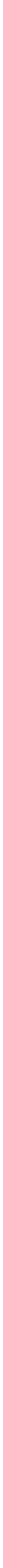